\title{
Emotional intelligence as a predictor of marital adjustment to infertility
}

Jalil, Tabinda

Department of Psychology, Lahore College for Women University, Pakistan (tabinda.jalil@yahoo.com)

Muazzam, Amina

Department of Psychology, Lahore College for Women University, Pakistan (amina_muazzam@ @otmail.com)

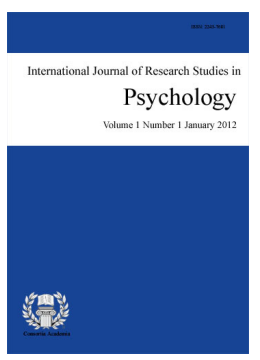

ISSN: $2243-7681$ Online ISSN: 2243-769X

OPEN ACCESS

\section{Abstract}

The purpose of the present research was to investigate whether emotional intelligence predicts marital adjustment in fertile and infertile women. A positive relation between the two variables was hypothesized. The study sample consisted of 120 fertile and 120 diagnosed infertile women; with the pre-requisite condition that minimum duration of marital relation without children should be two years. The age range of participants was 20 to 40 years. Marital Adjustment Questionnaire (Kausar, \& Khalid, 2003) was used to assess marital adjustment of the two groups. Whereas, emotional intelligence of the participants was assessed with Schutte's (1990) Emotional Intelligence Scale and was translated into Urdu. The results of the study revealed a significant relationship between emotional intelligence and marital adjustment in both groups. The comparison of two groups showed that fertile women's marital adjustment was better than infertile women. Results also suggested emotional intelligence as predictor of marital adjustment.

Keywords: emotional intelligence (EI), marital adjustment (MA), infertility, fertile women, infertile women 


\section{Emotional intelligence as a predictor of marital adjustment to infertility}

\section{Introduction}

Emotional intelligence (EI) and marital adjustment (MA) has been focus of study during the last decade. Marital adjustment in relation to infertility has also been the issue of investigation for the researchers. Infertility affects the marital relationship of couples, especially women with infertility face familial and societal pressures regarding childlessness. They go through stress and emotional distress. Emotionally intelligent people can better handle their relationships. They are not only aware of their emotions but feelings of others as well (Mayer \& Salovey, 1990). Proficiency in emotional intelligence helps an individual make his/her relationships productive and strong. Emotionally intelligent people are better able to resolve their conflicts as compared to others. This is the reason they are able to deal with their marital issues intellectually than those with lower EI. Infertility is considered a stressor or trauma for the couple facing this unexpected hurdle in the journey of their new life. The affected couple goes through emotional disturbances and societal pressures in many cultures. The focus of current study was to investigate the role of emotional intelligence in marital relationship of "women with infertility".

Fecundity (fertility) means ability of a woman to conceive a child. Women with impaired fecundity have complications in conceiving a child. Medical definition of infertility describes it as "inability of couples to conceive after 12 months of regular intercourse without contraception". The time duration of one year is preferred because normally it may take 12 months for a couple to conceive. Therefore the investigations are started after one year so that the reason for not conceiving can easily be found out. Thus, unnecessary investigations are not made (Alexander, Bader, Garfield, \& LaRosa, 2007, p. 226). Infertility rate is increasing in Pakistan. "About 8\% of Pakistani population is facing infertility issues, while $90 \%$ causes of the disease are curable and only 10 percent are complicated" described Imtiaz (as cited in Khan, 2010).

Infertility should be considered as problem of a couple and not that of female or male only. Since the factors that lessen fertility are shared; both partners should be examined when beginning an infertility treatment. Infertility treatments are commonly available now and emerging technologies have made it possible for couples to have a child (Alexander et al., 2007, p. 231). There are 2 types of infertility; Primary infertility and Secondary infertility. Primary infertility is the condition in which a couple failed to conceive even once. Whereas, secondary infertility refers to the condition where a couple successfully conceived at least once, but remained unsuccessful after that. The underlying cause of not conceiving can be in either partner. There are different causes for infertility. Female infertility can be the result of ovulation problems, polycystic ovarian syndrome, Endometriosis, or blocked fallopian tubes (Chohan, 2010, p. 129).

Infertility and its treatment methods are very stress provoking for the couples going through it. In some cases women going through all these difficult procedures develop the anger and resentment towards their spouses, especially if their spouses are less concerned about them. When the couple goes for the treatment procedures, it may develop expectations for having children, but at the same time it may also feel grief and uncertainty about whether it would be successful. This amalgamation of emotions may sometimes create misunderstanding between the couple. Women are psychologically more affected by infertility than men. They may undergo depression. In addition, infertility treatments are very expensive, and it may not be feasible for every couple to afford these expenses (Alexander et al., 2007, pp. 229-230).

Marriage is a process in which a constant interaction of husband and wife occurs, and they mutually react to a never-ending sequence of new stimuli. Marriage means making adjustments to different aspects of life. Though marriage results in an intimate relationship but there are some factors that demand adjustments from the couple (Kirkpatrick, 1955). Marriage is defined by E.W. Burgess and H. J. Locke (1960) as a social affair. Marriage 
Emotional intelligence as a predictor of marital adjustment to infertility

implies a ceremony, a union with social sanctions; recognition of obligations to the community assumed by those entering this relationship (p. 6).

A couple has to face challenges with the beginning of marital relationship. It needs both external and internal adjustments after marriage. External adjustments refer to making adjustments to fulfill the societal demands. Society's needs and expectations may conflict with couple's need and requirements, whereas, internal adjustments refer to adjusting to different personalities of each other (Kirkpatrick, 1955, p. 433). Burgess and Locke (1960) defined a well-adjusted marriage as "a union where the attitudes and the acts of husband and wife are in agreement on the chief issues of marriage...." (p. 383).

Communication between husband and wife is considered an important factor for marital adjustment. Communication theorists propose that unclear communication can be a source of disturbed relationships. The newly married couple faces communication problem. Both partners may easily comprehend each other's communication but sometimes it becomes a hindrance in the development of relationship. One of the partners may not understand the hidden meanings of what is being said. An effective communication takes place when the sign or symbol generates the same meanings in the other partner as in the partner who communicated them (Kirkpatrick, 1955, p. 435).

Marital adjustment is actually the adjustment to some important matters of life. A well-adjusted couple has consensus on financial matters and most importantly how to deal with in-laws. The couple has to change its' preferences, interests, and aims of life. They share love, and give confidence to each other. And as a result of these adjustments they either reduce or stop complaining about their marriage (Burgess \& Locke, 1960, p. 384).

Burgess and Locke (1960) have described some pre-marital and post-marital predictors of marital adjustment. Premarital factors that contribute to marital adjustment include greater level of happiness of parent's marriage, how much happy a person was in his/her childhood and number of years of education a person has acquired and many others. All these factors are considered to be linked to a flourishing marital relationship. Whereas, post-marital factors that affect marital adjustment include having or not having any children, possessing a house, and whether the husband is doing any job. Personal characteristics and wish for having kids after marriage are also considered some factors that affect marital adjustment (p. 406).

Childlessness is one of the reasons that affect marital stability, especially in our culture. The couple who faces this issue has to confront familial and societal pressures regarding infertility. In our Pakistani society, family usually pressurizes husband to go for second marriage for the sake of having children. This creates distress and insecurity, regarding marital relationship, in women. Due to problem of childlessness, couple often indulges in certain behaviors (e.g. miscommunication etc.) that will eventually cause divorce or separation. Thus, it is necessary for stable marital relationship that husband and wife should be emotionally strong and intelligent enough to tackle their problems in an effective manner (Dimpka, 2010, p. 194). Burgess and Locke (1960) while describing predictors of marital adjustment mentioned childlessness or wish for having children as important predictor (p. 406).

Infertility whether it's of any kind, affects couples', especially a women's life. The failure to reproduce not only subverts the marital relation, but it also affects the women's position in society. Dealings with friends and family are changed. Women face emotional harassment in homes e.g. they are isolated from the family celebrations, they are stigmatized, health care is not provided as before, and sometimes negative attitudes e.g. beating is faced by these women (Ali \& Sami, 2006, p. 19).

Marital adjustment in relation to infertility has frequently been the issue of investigation for the researchers. Research shows that infertility leads to marital conflict and discontentment with the marital relation. Women with infertility face more marital conflict than infertile men (Sultan, 2010, p.31). Infertility not only affects marital adjustment but quality of life as well (Ganiata, Monga, Seth, \& Stein, 2004, p. 126). Research has also revealed that uneducated infertile females were less psychosocially adjusted than educated infertile females 
(Parveen et al., 2008, p. 108). Burgess and Locke (1960) described predictors of marital adjustment. One of these main factors that affect martial adjustment is childlessness or wish for having children (p. 406).

Emotions play a significant role in our lives. We converse and interact with others using either verbal or non-verbal expression of our emotions. These expressions make others easy to understand our feelings. And in turn our interaction with people becomes more effective (Feldman, 2005, p. 346). Mayer and Salovey (1990) defined emotional intelligence as "the ability to monitor one's own and others' feelings and emotions, to discriminate among them and to use this information to guide one's thinking and actions" (p. 189). Mayer and Salovey in their 1990's model of emotional intelligence described three important components of emotional intelligence which include appraisal and expression of emotions in self and others, regulation of emotions in self and others, and using emotions in an accustomed way (pp. 191-198).

Daniel Goleman (1995) describes emotional intelligence as managing feelings so that they are expressed appropriately and effectively, enabling people to work together smoothly toward their common goals. According to Goleman (1995) skills that make an individual emotionally intelligent are self-awareness, self-management, social awareness, and relationship management (as cited in Chapman, 2007).

In 1997, Mayer and Salovey modified their definition of emotional intelligence. Another component into their model was added i.e. emotional facilitation of thinking. This component of their theory tells about emotions influence our intellectual development and they can be used to facilitate our thoughts. Mayer and Salovey's model (1997) holds the view that those who are emotionally intelligent can recognize, understand their and others' emotions, use emotions to facilitate thinking, and can manage their emotions. The first component reflects that an emotionally intelligent individual can identify his/her own and others' feelings and emotions. This involves understanding emotions expressed through facial expression, voice tone, and other body gestures. They can interpret and convey feelings to others in an intellectual manner and can differentiate between original and fake expressions of emotions (Mayer \& Salovey, 1997, p. 10). In addition to these characteristics, individuals with high emotional intelligence are able to sensibly grasp the real connotations of emotions. They are proficient in dealing with emotions, and managing their reactions to these emotions e.g. showing tolerance or patience towards negative emotions of oneself and others. They have skills to observe one's and other's emotions and showing positive attitudes towards feelings that are either positive or negative without overstating or understating their meanings (Mayer \& Salovey, 1997, p. 13).

In the beginning of marital relationship, each partner tries to give its best to his/her relation. Negative emotions are controlled and the person tries to do everything for the life partner. But after some time, all these efforts slow down. This happens because emotional intelligence is no more being utilized. Love and happiness only comes when an individual knows how to maintain good relationships. For making a relationship healthy and strong certain competencies are required. These competencies are not in-born; instead they are and can be learned with the passage of time. Those who are emotionally intelligent are able to build life-long relationships. These competencies help people develop tolerance and cope with life stressors as they affect the partner, themselves and the relationship. Emotional intelligence facilitates recognizing one's own motivations, feelings and desires which is important in effective communication to a partner. A person's ability to accurately identify what others think, resolving conflicts and repairing wounded feelings are all those competencies necessary for maintaining good relationships (Stephenson, 2008).

Segal (2009) describes some important emotional intelligence skills that would facilitate strong relationships. These skills include developing trust and safety, capturing others' attention and interest, showing empathy and kindness towards others, communicating proper non-verbal messages, and resolving conflicts.

Aktinson (2005) have suggested married couples some important EI tips for marital adjustment. He suggests that if someone experiences a negative behavior of his/her partner, he/she should consider that there must be some legitimate reason behind their partner's actions. In addition, personal preferences of the partner behind his/her actions should also be found out. This doesn't mean that the person's own issues are not important. 
Spouses should respect each other's desires and emotions. One of the spouses should try to discover and express the core desires, reservations and uncertainties at the back of agony once he/she is relaxed after an upsetting behavior of the other spouse. Successful couples are capable enough to recognize their inner condition to resolve which factors are creating problems.

Batool and Khaild (2012) studied whether emotional intelligence predicts marital quality of couples. The results showed that emotional intelligence significantly predicts marital adjustment. The findings revealed a significant positive relationship between emotional intelligence and indicators of marital quality i.e. marital adjustment and conflict resolution. Interpersonal skills, empathy, optimism, and impulse control appeared be significant predictors of marital quality.

Dildar, Bashir, Shoaib, Sultan, and Saeed (2012) concluded positive relationship between EI and marital adjustment $(r=.65)$. Couples with high EI were found to be more adjusted in their life as compared to those with low EI. Good communication skills positively contributed to marital adjustment of the couples. Women were found to be more intelligent in expression of their emotions than men. It was also concluded that family income had direct relation to marital adjustment.

Women are usually considered, by others as well as themselves, as the emotional providers of the relationships. Women generally have strong sense of guilt. They consider themselves accountable for others' unpleasant feelings and whatever wrong happens to them. Suppression of inner feelings makes them depressive and thus they feel out of control. When a women goes through the stress of infertility she blames herself for the inability to conceive and undergoes the extreme emotional feelings like denial, pain, stress, grief, and anger, and isolation. In some cases women may suffer from major depression. (Evert, 2007). Emotional intelligence enables people to control their emotion. Various researchers have shown in their study the importance of emotional intelligence in marital relation.

Golzary and Yazdi (2005) conducted research that revealed that an individual's ability to understand others' emotions, express his/her own emotions in a positive way, showing concerns for each other, and to control and manage emotions in an efficient manner results in a successful marital relation. Mood and interpersonal aspects were proven as predictors of marital adjustment. Joshi and Thingujam (2009) studied perceived EI and MA of participants while investigating the arbitrating role of personality and social desirability. Results showed relationship between EI and MA suggesting that emotionally intelligent couples are well adjusted in their marital relationships. Nicole Schutte (2001) carried out studies regarding the relationship between marital satisfaction and EI. The results showed a significant relationship between the two variables. Buck, Lieberman, Raval, and Slade (1992) studied the impact of infertility on marital and emotional functioning. The results showed a decline in self-esteem. Marital and emotional adjustments were also decreased. It was also found that repeated failures of the treatment damaged the relationship of spouses. As the infertility period increased marital life deteriorated

\subsection{Hypotheses}

The focus of current study was to investigate following hypotheses:

$>\quad$ There is a positive relationship between emotional intelligence and marital adjustment of women with infertility.

$>\quad$ There is a positive relationship between emotional intelligence and marital adjustment of fertile women.

$>\quad$ There is difference in marital adjustment of fertile and infertile women.

$>\quad$ There is difference in marital adjustment of infertile women regarding educational level.

$>\quad$ There is difference in marital adjustment of fertile women regarding educational level. 
$>$ Emotional intelligence is a predictor of marital adjustment of infertile women.

$>$ Emotional intelligence is a predictor of marital adjustment of fertile women.

\section{Method}

\subsection{Sample}

The study sample consisted of 240 participants. The sample consisted of two groups; married fertile women $(N=120)$, and women with diagnosis of infertility $(N=120)$ selected through purposive sampling technique. The age range for the participants was 20 to 40 years $(M=30.10, S D=4.20)$. The sample of the study included women with fertility problems with the condition that minimum duration of marital relation without children should be two years. Married women, attending the infertility clinics or gynecological departments of various government and non-government hospitals of Lahore were included. Women diagnosed either primary or secondary infertility were part of the study. Women below 20 or above 40 years of age were not included in the sample. Women who already have adopted children were not part of the study. Demographic information regarding age, qualification, monthly income, occupation, husband's occupation, duration of marital relation, primary/secondary infertility, and joint/nuclear family structure was obtained from the participants.

\subsection{Instruments}

\subsubsection{Marital Adjustment Questionnaire (MAQ)}

MAQ (Kausar \& Khalid, 2003) consists of 45 items. The scale is based on Burgess Marriage Adjustment Schedule (1960). MAQ assesses the nature of affiliation with in-laws, how the spare time is spend with the spouse, how much considerate the spouses are for each other, their satisfaction with the marriage as well as with in-laws. Respondents answer on a three point scale. For some items scoring was reversed. Total score of the subject was obtained by adding all the scores on all of 45 items. Alpha coefficient obtained on the scale was 0.90 .

\subsubsection{Emotional Intelligence Scale (EIS)}

EIS (Schutte, 1998) is a five point rating scale, consisted of 33 items. It is based on Mayer and Salovey's 1990 model. Total scores of the scale are calculated by reversing some items' score and then adding all items. Score range is from 33 to 165 , with higher scores indicating more characteristic emotional intelligence. The scale was translated in to Urdu language. The reliability coefficient of the scale for the current data is alpha 0.91.

\subsection{Procedure}

The study consisted of two parts. In the first part of the study, Emotional Intelligence Scale (Schutte, 1998) was adapted and validated. The items of the scale were presented to bilingual educators in order to translate each item in such a way that the conceptual meaning contained in each item was adequately conveyed through the items in Urdu. The translated scale was then examined for accuracy of conceptual meaning. Those items which had similar conceptual meanings to that of items in original scale were kept in translated scale. Then cultural relevance of each item was also assessed. The translated scale was then given to 10 participants who confirmed that each item was relevant to Pakistani culture and was thus considered as the final format of the scale. The translated version of 33-items Emotional intelligence scale was used for the purpose of the present study. The reliability and validity of the scale was also determined by administering the scale to participants. For translated scale reliability co-efficient was found .91 whereas the original scale has reliability coefficient 0.90 .

In the second part of the study, data was collected from fertile and infertile women. For the purpose of data collection, approval of the study was taken from departmental research ethics committee of the parent institute. 
Thereafter, participants (women with infertility) were approached after taking permission from the authorities of gynecological departments of hospitals in Lahore. Informed consent of the participants was taken. After giving necessary instructions, demographic sheet and questionnaires were administered. Confidentiality of the information taken from the participants was assured.

\section{Results}

In the present study analyses for the fertile and infertile group were run separately. Analysis of demographic variables shows that age of infertile participants ranged from 20 years to 40 years $(M=29.58, S D=4.3)$ whereas educational qualification ranged from 8 years to 18 years $(M=14, S D=1.8)$. Total 50.8\% cases were of primary infertility, whereas remaining cases were of secondary infertility. $40.8 \%$ of infertile participants were working women whereas remaining were house wives. Fifty percent of the participants' monthly family income ranged from 26,000 to 50,000 Rupees. $54.2 \%$ of women belonged to joint family system and $45.8 \%$ belonged to nuclear family system. Maximum duration of marriage period was 13 years. $65.8 \%$ women were married out of family.

Whereas in the fertile group mean age of the participants was $30.6(S D=4) .56 .7 \%$ of participants were working women. Among total family income the highest percentage (70\%) lies within 26000 to 50000 Rupees. Participants belonging to joint family system were $55 \%$ whereas $45 \%$ live in nuclear family system. $84 \%$ women were married out of family. The longest duration of marriage was 20 years.

The results of the present study show that women with infertility sometimes feel insecure regarding their marriage. Eighty percent women with infertility, as compared to $56.7 \%$ fertile women, reported that their unmarried life was better than the married life. This high percentage of response depicts the effects of infertility. Childless women in our society are neglected and face societal pressures for not having children. 66.6\% women with infertility reported their husbands are somewhat interested in second marriage. This shows that there is so much societal pressure on the childless couple, even parents sometimes pressurizes their sons to go for second marriage for having children. Threats for divorce is also given when the women is unable to conceive. These results are in harmony with Sami and Ali's (2006) results which concluded that women with infertility, regardless of its type, face poor marital adjustment. They are given threats for divorce or their husbands show interest in second marriage. Dimpka (2010) also reports the same findings in his work.

To examination the relationship between emotional intelligence, marital adjustment and other demographic variables correlation analysis was computed. Summary of correlations as well as Mean and Standard Deviation of the study variables is given in the Table 1 .

\section{Table 1}

Summary of intercorrelations, means, standard deviation of the study variables

\begin{tabular}{|c|c|c|c|c|c|c|c|}
\hline Variables & 1 & 2 & 3 & 4 & 5 & $M$ & $S D$ \\
\hline 1. MA & - & $0.50 * *$ & $0.43 * *$ & $0.23 *$ & -0.16 & 94.8 & 10.66 \\
\hline 2. EI & $0.58 * *$ & - & $0.41 * *$ & $0.21 *$ & 0.19 & 101.7 & 14.91 \\
\hline 3. Education & $0.43 * *$ & $0.20 *$ & - & $0.40 *$ & -0.01 & 14.18 & 1.85 \\
\hline 4. Monthly Income & $0.34 * *$ & -0.09 & 0.07 & - & 0.19 & 30208.3 & 13352.3 \\
\hline 5. Marital Duration & -0.07 & 0.00 & -0.17 & -0.02 & - & 5.96 & 3.35 \\
\hline$M$ & 114.74 & 125.85 & 14.53 & 41258.33 & 6.78 & & \\
\hline$S D$ & 7.36 & 10.04 & 2.166 & 14144.21 & 4.04 & & \\
\hline
\end{tabular}

Note. $\mathrm{MA}=$ Martial Adjustment; EI= Emotional Intelligence. $\quad * p<.05, * * p<.01$. 
In Table 1, intercorrelations for infertile group are presented above the diagonal, whereas for the fertile group these are presented below the diagonal. Means and standard deviations for infertile groups are presented in vertical columns, and means and standard deviations for the fertile group is presented in the horizontal rows. Results indicate that women with infertility showed a significant positive correlation between MA and EI ( $r$ $=.50, p<.01)$. Whereas, the comparison group also showed significant positive correlation between MA and EI $(r=.58, p<.01)$. Monthly income and marital adjustment are also positively correlated. Results also revealed that education positively contributes to marital adjustment. Table 1 shows negative relationship $(r=-.16)$ between marital adjustment and duration of marriage in infertile women, suggesting that as the period of infertility increases, marital adjustment becomes poor. The hypothesis is hence accepted for the infertile women's group.

It was hypothesized that there would be a positive relation between marital duration and marital adjustment of fertile women. In order to compare the results with the fertile women's results, correlation for comparison group was also computed. The results showed a negative relation between the two variables $(r=-.07)$ hence rejecting the hypothesis that as the marital duration would increase, marital adjustment would also increase. In order to find out the difference in marital adjustment of fertile and infertile women $t$-test was computed. The results of independent sample $t$-test show significant difference between infertile and fertile women's martial adjustment. Comparison of means of two groups showed better marital adjustment of fertile women $(M=114.74$, $S D=7.36)$ than infertile women $(M=94.80, S D=10.65), t(238)=-16.86)$.

\subsection{Martial adjustment of women regarding education level}

Keeping proposition in mind that education contributes to marital adjustment it was hypothesized that women with higher level of education would better be adjusted to marriage than women with lower level of education. To explore this proposition, One-way Analysis of Variance was employed. ANOVA resulted in significant difference of Marital Adjustment in relation to education level of infertile and fertile group (Tables 2 \& 3).

Table 2

One way analysis of variance of marital adjustment of infertile women regarding education level

\begin{tabular}{|c|c|c|c|c|c|c|c|c|c|c|c|c|}
\hline \multirow{2}{*}{ Measures } & \multicolumn{3}{|c|}{ Under graduate (1) } & \multicolumn{3}{|c|}{ Graduate (2) } & \multicolumn{3}{|c|}{ Post - graduate (3) } & \multirow{2}{*}{$F$} & \multirow{2}{*}{$p$} & \multirow{2}{*}{ Post Hoc } \\
\hline & $n$ & $M$ & $S D$ & $n$ & $M$ & $S D$ & $n$ & $M$ & $S D$ & & & \\
\hline MA & 32 & 86.84 & 9.63 & 46 & 96.3 & 8.45 & 42 & 99.21 & 10.46 & 16.32 & 0.000 & $3>1,2 *$ \\
\hline
\end{tabular}

Note. *ategories of education i.e. 1, 2, 3

A significant difference was found in marital adjustment of infertile women regarding educational level as shown in Table 2. Graduate infertile women's marital adjustment was better than undergraduate infertile women's marital adjustment. Whereas, women with post-graduate level of education showed better marital adjustment than women with graduate level of education. Similar results were found in the comparison group (Table 3).

\section{Table 3}

One way analysis of variance of marital adjustment of fertile women regarding education level

\begin{tabular}{|c|c|c|c|c|c|c|c|c|c|c|c|c|}
\hline \multirow{2}{*}{ Measures } & \multicolumn{3}{|c|}{ Under graduate (1) } & \multicolumn{3}{|c|}{ Graduate (2) } & \multicolumn{3}{|c|}{ Post - graduate (3) } & \multirow{2}{*}{$F$} & \multirow{2}{*}{$p$} & \multirow{2}{*}{ Post Hoc } \\
\hline & $n$ & $M$ & $S D$ & $n$ & $M$ & $S D$ & $n$ & $M$ & $S D$ & & & \\
\hline MA & 31 & 108.94 & 7.96 & 29 & 115.62 & 5.92 & 60 & 117.32 & 5.97 & 17.19 & 0.000 & $3>1,2 *$ \\
\hline
\end{tabular}

Note. *Categories of education i.e. 1,2,3.

Martial Adjustment scores of women with post graduate level of education were higher than the scores of 
graduate and under graduate women.

In the present study hierarchical multiple regression analysis was used to find out the interaction between marital adjustment and emotional intelligence. Two separate regression analysis was conducted for infertile and fertile groups (Tables 4 \& 5). For infertile group (Table 4), Emotional intelligence was entered in the first step, subsequently husband's education and occupation in the second, age, education, and monthly income in the third and family system and marriage duration in the fourth step. Emotional intelligence accounted for $25 \%$ of variance in marital adjustment of the infertile group $(\beta=0.50, p<.01)$. Husband's education and occupation accounted for $62 \%$ variance in MA. Education and monthly income significantly predicted marital adjustment and accounted for $66 \%$ variance in MA. Whereas $70 \%$ of variance was explained by family system and marriage duration for the marital adjustment.

\section{Table 4}

Multiple regression analysis predicting marital adjustment of women with infertility

\begin{tabular}{llllll}
\hline Step and predictor variable & $B$ & $S . E$. & $\beta$ & $R^{2}$ & $\Delta R^{2}$ \\
\hline $\begin{array}{l}\text { Step } 1 \\
\text { Emotional intelligence }\end{array}$ & 0.36 & 0.06 & $0.50^{*}$ & 0.25 & $0.25^{*}$ \\
Step 2 & & & & 0.62 & $0.37^{*}$ \\
$\quad$ Husband's education & 10.26 & 0.97 & $0.70^{*}$ & & \\
$\quad$ Husband's occupation & -0.12 & 0.55 & -0.01 & & $0.04^{*}$ \\
Step 3 & & & & 0.66 & \\
$\quad$ Age & 0.13 & 0.16 & 0.05 & & \\
$\quad$ Education & 1.15 & 0.39 & 0.20 & & $0.04^{*}$ \\
$\quad$ Monthly income & 0.00 & 0.00 & $(* *)-0.15$ & & \\
Step 4 & -2.69 & 1.20 & & & \\
$\quad$ Family system & -1.01 & 2.77 & $*-0.32$ & & \\
$\quad$ Marriage duration & & & &
\end{tabular}

Note. $B=$ beta coefficient. $\quad * p<.01, * * p<.05$

A separate multiple regression analysis was computed for data collected from fertile women. Results are shown in Table 5. Emotional intelligence accounted for $33 \%$ of variance in marital adjustment of the fertile women $(\beta=0.58, p<.01)$. Husband's education and occupation accounted for $69 \%$ variance in MA. Education and monthly income significantly predicted marital adjustment and accounted for $75 \%$ variance in MA. Whereas, $75 \%$ of variance for marital adjustment was explained by family system and duration of marriage.

\section{Table 5}

Multiple regression analysis predicting marital adjustment of fertile women

\begin{tabular}{|c|c|c|c|c|c|}
\hline Step and predictor variable & $B$ & S.E. & $\beta$ & $R^{2}$ & $\Delta R^{2}$ \\
\hline Step 1 & & & & $0.33 *$ & $0.33 *$ \\
\hline Emotional intelligence & 0.42 & 0.06 & $0.58 *$ & & \\
\hline Step 2 & & & & 0.69 & $0.36^{*}$ \\
\hline Husband's education & 6.40 & 0.64 & $0.61 *$ & & \\
\hline Husband's occupation & -0.33 & 0.47 & -0.04 & & \\
\hline Step 3 & & & & 0.75 & $0.06 *$ \\
\hline Age & -0.10 & 0.09 & -0.05 & & \\
\hline Education & 0.66 & 0.20 & $0.19 *$ & & \\
\hline Monthly income & 8.49 & 0.00 & $0.16^{* *}$ & & \\
\hline Step 4 & & & & 0.75 & $0.00 *$ \\
\hline Family system & -0.50 & 0.77 & -0.03 & & \\
\hline Marriage duration & 0.03 & 0.15 & 0.02 & & \\
\hline
\end{tabular}

Note. $B=$ beta coefficient. $\quad * p<.01, * * p<.05$ 


\section{Discussion:}

It seems as if marriage is a complex process and adjustment to it is a challenge for the couple especially for the female partner. No doubt emotional intelligence plays role of an effective tool for success in this process. A couple sometimes has to face many challenges in its life and if it is infertility, it can have devastating effects on the couples' life. Women with infertility are more prone to psychological distress than man. Martial adjustment is already a difficult process, and adjustment with infertility makes it even more difficult. Women have to face social and familial pressures. They are given threats for second marriage by their husband. All these pressures in addition to long-term and expensive treatment methods for infertility lead to a very depressive life.

The major findings of the present research show that 'Emotional Intelligence' is a predictor of marital adjustment. The results confirm that infertility affects marital relationship, hence affecting marital adjustment.

The present study's main focus was to examine how infertility affects marital adjustment and to find out the mediating role of emotional intelligence. In order to find out the relationship between emotional intelligence and marital adjustment a positive relationship between the two was hypothesized. The findings of the current study supported the hypothesis and are consistent with the results obtained by Gardner (2011); Batool and Khalid (2009); Joshi and Thingujam (2009); Bricker (2005); Brackett, Warner, and Bosco (2005); and Schutte (2001). They all concluded that emotionally intelligent people are better able to handle their relationships. In Pakistani culture social set-up is different from other cultures. Mostly arranged marriages are held in our society and women are usually unaware of the family set-up of their in-laws. They are not familiar with the family background of their in-laws, especially their life partner. In-laws expectations towards the girls, who are going to become a part of their family, are higher. They expect girls to be changed for them. All these factors create difficulty in making adjustments in a new environment. In such a situation emotional intelligence plays an important role. People who are emotionally intelligent are better able to handle their marital issues. Joshi and Thingujam (2009) also reported the same findings in their research that emotionally intelligent couples can better handle their marital life. They are better able to understand spoken and unspoken words. Their ability to effectively deal with own and others' emotions make them able to manage their conflicts. And by "utilizing emotions" they can create happiness for their spouse. Thus Emotional Intelligence helps in making adjustments to and facilitation in marital relationship.

To examine the relationship between marital adjustment and economic level, a positive correlation between these two variables was hypothesized for both groups. Results revealed that economic level has a significant role in marital adjustment. These results are in harmony with what Dawood and Farooqi (2000) found in their study. The treatment for infertility is very costly. If the individual has insufficient finances, it would be difficult to begin or continue the treatment. And consequently this financial difficulty would act as hindrance on the way to fertility and this would affect the marital relation of the couple. That is why finances are important in infertility. Similarly, fertile women's results also indicated a significant role of finances in marital adjustment. This is because couples who are financially strong can meet the needs of their life in a better way than those with lower economic status.

Another hypothesis of the study was regarding negative relation between marital duration and marital adjustment of women with infertility. The results supported the hypothesis by revealing negative relation between marital adjustment and marital duration of women with infertility (Benazon, Sabourin, \& Wright, 1992; Buck et al., 1992). The reason behind it is as the infertility period increases; the person facing this problem faces more societal pressures and stressors, which in turn affect marital adjustment. For comparing results regarding marital duration and marital adjustment, the correlation analysis was run regarding positive relation between marital adjustment and marital duration in fertile women but no significant relationship was found between the two variables. These findings are in contradiction with Bali, Dhingra, and Baru's (2010) study results where a positive correlation between marriage duration and marital adjustment is found. They concluded that with the increase in marital duration, marital adjustment increases. 
A difference between MA of infertile women and fertile women was hypothesized. The present research findings supported the hypothesis and showed a significant difference in Marital Adjustment of fertile and infertile women. The comparison of means of two groups disclosed that marital adjustment of fertile women was better than infertile women, which means that infertility affects marital life. Previous researches and literature have also shown the same findings that infertility affects marital relations (Benazon et al., 1992; Faghihi, Ghashang, Kayghobadi, Mazaheri, \& Pato, 2001; Ganiata et al., 2004; Ali \& Sami, 2006). These researches have shown that childlessness affects couple's relationships. The reason behind it is childless couple has to answer people's questions regarding not having any child. This thing creates stress for the couple specifically for woman who starts blaming herself, undergoes depression, may aloof herself from society and consequently develops feelings of loneliness. Threats for divorce are also given to women. Husband's attention towards the wife is decreased. All these factors affect the marital relation.

Education helps awareness and increases the wisdom of an individual. People keep on learning ways to interact with others. An educated person can better understand others as compared to an uneducated person. Keeping this in mind difference in marital adjustment of women regarding education level was proposed. Post graduate women showed better marital adjustment than graduates and undergraduate. The results supported the hypothesis. Previous research findings are in harmony with this hypothesis (Parveen et el., 2008; Jaswal, Singh, \& Thind, 2006; Dawood \& Farooqi, 1997). Therefore it can be suggested that infertile women with higher level of education are better able to handle their marital issues than those with lower level of education.

While finding the predictors of marital adjustment Emotional Intelligence was taken as a predictor. The results have shown that Emotional Intelligence is a predominant predictor of marital adjustment in fertile as well as infertile women. Emotional intelligence accounted for $25 \%$ of variance in marital adjustment of the infertile women. Researches and literature have supported that emotional intelligence plays an important role in management of marital relations (Golzary \& Yazdi, 2005). Results of the study conducted by Batool and Khaild (2012) are also in line with the present study findings that emotional intelligence predicts marital adjustment. Therefore it might be suggested that women with emotional intelligence skills are better able to adjust to marital relationship.

The current research finding revealed that husband's education predicts marital adjustment of infertile women. Husband's education and occupation accounted for 62\% variance in MA. Burgess and Locke (1960) found in their research that education of husband is one of the predictors of marital adjustment. Our society is a male dominating society and men are supposed to run the family. They are the financial providers. It is very important for the head of the family to be educated because education shapes an individual's personality, and enables an individual to manage family affairs. Husband's occupation also plays an important role as it is signifies importance of finances.

Income is an important factor in marital adjustment of people with infertility because money is needed for expensive treatment procedures. In the present study education and monthly income significantly predicted marital adjustment and accounted for 66\% variance in MA of infertile women. Ali and Sami (2006) reported that women with infertility are not only emotionally harassed but they are deprived of medical facilities as well. Dawood and Farooqi (2000) explored in their study that women belonging to higher socio-economic status that are better adjusted to martial life than those from lower socio-economic status. This shows that finances are of major concern for the treatment of infertility. Literature has also shown the importance of finances in marital life (Allgood, Kerkmann, Thomas, \& Lown, 2000; Kazmi, Pervez, \& Ijaz, 2010; Dildar et al., 2012). These studies have concluded that satisfaction with marital life is predicted by financial resources.

Seventy percent variance was explained by family system and marriage duration for the marital adjustment of infertile women. Joint and nuclear family system is one of important factors that affect marital adjustment. Infertile women living in joint family system face more troubles than those living in nuclear family system as interference in joint family system is more than the nuclear family system. Pressure regarding infertility 
increases in joint family system where everyone is concerned about hearing 'good news' from the couple. As the marriage duration increases infertility period also increases, hence an increase in stress period.

\subsection{Practical implications:}

Fertility related issues would always be an important concern for health practitioners. With regard to implications of the present study the findings of the study would benefit health care professionals and counselors to understand the important role of emotional intelligence in marital life of infertile people, especially women. Since childless couples develop feelings of grief and loss that may eventually lead to depression, therefore this study expects that marital counseling in addition to infertility treatment be provided to infertile couples. Skills to enhance emotional intelligence may be taught as part of marital counseling. EI skills would help them become aware of their own and each other's emotions. Couples should be taught skills to increase their expression of emotions. Thus they would be able to manage their upsets in a better way. The significant relationship between emotional intelligence and marital adjustment is expected to divert attention of educational institutes towards introduction of emotion literacy program for the students in order to make them efficient in dealing with marital issues in future, hence leading to a strong family system.

Further research should be conducted with a larger sample to see the impact of infertility on marital adjustment. The results show poor marital adjustment and lower EI of infertile women as compared to fertile women. Advanced analysis is needed to find out the moderators of marital adjustment which would help in deciding either it is low EI or infertility that affects marital adjustment. A controlled study should be conducted in which family dynamics can be controlled as they also play role in marital adjustment

\section{Conclusion}

The present study was conducted to explore the relation between emotional intelligence and marital adjustment of women with infertility. The research findings conclude that emotional intelligence predicts marital adjustment. People who are emotionally intelligent can better understand and handle their own and others' emotions, and reactions towards these emotions as compared to those with low EI. They are better able to make adjustments in their marital life. Education and monthly income are also significant predictors of marital adjustment. It is also concluded that there is significant difference between infertile and fertile women's marital adjustment. Marital adjustment of fertile women is better than infertile women.

\section{References:}

Aktinson, B. (2005). Adult and relationship; emotional intelligence in marriage. Retrieved February 20, 2012 from http://www.drartluz.com/publications/emotional1.pdf

Alexander, L. L., Bader, H., Garfield, S., \& LaRosa, J. H. (2007). New dimensions in women's health (4 ${ }^{\text {th }}$ ed.). Canada: Jones and Bartlett.

Ali, S. T., \& Sami, N. (2006). Psychosocial consequences of secondary infertility in Karachi. Journal of Pakistan Medical Association. 56(1), 19-22

Allgood, S. M., Kerkmann, B. C., Lown, J. M., \& Thomas, R. L. (2000). Financial management, financial problems and marital satisfaction. Financial Counseling and Plotting, 11(2), 55-65. Retrieved March 10, 2011, from http://www.afcpe.org/assets/pdf/vol1126.pdf

Bali, A., Dhingra, R., \& Baru, A. (2010). Marital adjustment of childless couples. Retrieved January 1, 2013, from

http://www.krepublishers.com/02-Journals/JSS/JSS-24-0-000-10-Web/JSS-24-1-000-10-Abst-PDF/JSS24-1-73-10-385-Bali-A/JSS-24-1-73-10-385-Bali-A-Tt.pdf

Batool, S. S., \& Khalid, R. (2009). Role of emotional intelligence in martial relationship. Pakistan Journal of Psychological Research, 24(1-2), 43-62.

Batool, S. S., \& Khalid, R. (2012). Emotional Intelligence: A predictor of marital quality in Pakistani couples. 
Pakistan Journal of Psychological Research, 27(1), 65-88.

Benazon, N., Sabourin, S., \& Wright, J. (1992). Stress, sexual satisfaction, and marital adjustment in infertile couples. Journal of Sex and Marital therapy, 18(4), 273-284. http://dx.doi.org/10.1080/00926239208412852

Brackett, M. A., Bosco, J. S., \& Warner, R. M. (2005). Emotional intelligence and relationship quality among couples. Personality Relationships, 12(2), 197-212. http://dx.doi.org/10.1111/j.1350-4126.2005.00111.x

Bricker, D. (2005). The link between marital satisfaction and emotional intelligence. Unpublished master's thesis. University of Johannesburg, South Africa. Retrieved September 26, 2010, from https://ujdigispace.uj.ac.za/bitstream/handle/10210/1420/THESISFINAL14Feb2006.pdf? sequence=1

Buck, P., Lieberman, B. E., Raval, H., \& Slade, P. (1992). 3-year follow-up of emotional, marital and sexual functioning in couples who were infertile. Journal of Reproductive and Infant Psychology, 10(4), 233 243. http://dx.doi.org/10.1080/02646839208403956

Burgess, E. W., \& Locke, H. J. (1960). The family: From institution to companionship (2 ${ }^{\text {nd }}$ ed.). New York: American book Company.

Chapman, A. (2007). Emotional intelligence. Retrieved March 10, 2011, from http://searchcio.techtarget.com/definition/emotional-intelligence

Chohan, A. (2010). Fundamentals of Psychology. Pakistan; MAR.

Dawood, S., \& Farooqi, Y. (1997). Impact of females' education on their marital adjustment. Retrieved July 15, 2010, from http://www.uok.edu.pk/research_institutes/icp/images/abstracts.pdf

Dawood, S., \& Farooqi, Y. (2000). Role of socio-economic status as a factor in marital adjustment. Retrieved July 15, 2010, from http://www.uok.edu.pk/research_institutes/icp/images/abstracts.pdf

Dildar, S., Bashir, S., Shoaib, M., Sultan, T., \& Saeed, Y. (2012). Chains do not hold a marriage together: Emotional intelligence and marital adjustment (A Case of Gujrat District, Pakistan). Retrieved January 2, 2013, from http://idosi.org/mejsr/mejsr11(7)12/22.pdf

Dimpka, D.I. (2010). Marital adjustment roles of couples practicing child adoption. European Journal of Social Sciences, 13(2), 194-200.

Evert, J. (2007). Coping with infertility. Retrieved January 11, 2011 from http://www.mentalhelp.net/poc/view_doc.php?type=doc\&id=11292\&cn=65

Feldman, R. S. (2005). Understanding psychology ( $7^{\text {th }}$ ed.). New York: McGraw Hill.

Ganiata, T., Monga, M., Seth, E. K., \& Stein, M. (2004). Impact of infertility on quality of life, marital adjustment, and sexual function. Urology, 63(1), 126-130. http://dx.doi.org/10.1016/j.urology.2003.09.015

Gardner, A. T. (2011). Emotional intelligence in marriage. Retrieved February 13, 2011, from http://www.drtimgardner.net/Emotional-Intelligence-in-Marriage.html

Golzary, M., \& Yazdi, F. J. (2005). The relationship between emotional intelligence and marital adjustment among female teachers in Tehran. Retrieved January 20, 2011, from http://en.sbu.ac.ir/Portals/0/Family/4.pdf

Jaswal, S., Singh, R., \& Thind, S. K. (2006). Assessment of marital adjustment among couples with respect to women's educational level and employment status. The Anthropologist, 8(4), 259-266.

Joshi, S., \& Thingujam, N. S. (2009). Perceived emotional intelligence and marital adjustment: Examining the mediating role of personality and social desirability. Journal of the Indian Academy of Applied Psychology, 35(1), 79-86.

Kausar, R., \& Khalid. R. (2003). Relationship between conflict resolution strategies and perceived marital adjustment. Journal of Behavior Sciences, 14, 29-42.

Kazmi, F., Pervez. T., \& Ijaz, S. (2010). The role of economic resources on marital adjustment of women. Retrieved January 20, 2011, from http://www.researchgate.net/publication/215950765_THE_ROLE_OF_ECONOMIC_RESOURCES_I N_MARITAL_ADJUSTMENT_OF_WOMEN_IN_THE_PROVINCE_KHEBER_PAKHTOON_KHA WA_(KPK)

Khan, A. (2010, April 10). Infertility rate increases in Pakistan. The Nation, p.10. 
Jalil, T. \& Muazzam, A.

Kirkpatrick, C. (1955). The family: As process and institution. New York: The Ronald press

Mayer, J. D., \& Salovey, P. (1990). Emotional Intelligence. Retrieved July 20, 2011, from http://www.unh.edu/emotional_intelligence/EIAssets/EmotionalIntelligenceProper/EI1990\%20Emotion al\%20Intelligence.pdf

Mayer, J. D., \& Salovey, P. (1997). What is emotional intelligence? In P. Salovey \& D. Sluyter (Eds), Emotional development and emotional intelligence: Implications for educators (pp. 3-31). New York: Basic Books

Parveen, B., Ahmed, I. D., Kousar, S., Musharaf, S., Masood, A., \& Afzal, S. (2008). Psychosocial adjustment of educated and uneducated infertile females of Pakistan. Annals of Punjab medical college, 2(2), $108-112$.

Schutte, N. S., Malouff, J. M., \& Bhullar, N. (2009). The assessing emotions scale. In C. Stough, D. Saklofske, \& J. Parker (Eds.), The assessment of emotional intelligence (pp. 119-135). New York: Springer Publishing. http://dx.doi.org/10.1007/978-0-387-88370-0_7

Schutte, N. S., Malouff, J. M., Bobik, C., Coston, T. D., Greenson, C., Jedlicka, C., Rhodes, E., Wendorf, G. (2001). Emotional Intelligence and interpersonal relations. The Journal of Social Psychology, 141(4), 523-536. http://dx.doi.org/10.1080/00224540109600569

Segal, J. (2009). What is emotional intelligence? Retrieved June 1, 2010, from http://www.emotionalintelligencecentral.org/eq/emotional_intelligence.html

Stephenson, K. (2008). Emotional intelligence in relationships. Retrieved March 10, 2010, from http://couplescounselling.suite101.com/article.cfm/emotional_intelligence_in_relationships

Sultan, S. (2010). Marital discord; the hidden burden of infertility. Pakistan Journal of Psychological Research, 25(1), 31-43. 